\title{
Relationship between clinical data and gene expression in the HER2/ErbB2-dependent signaling pathway in patients with acute heart failure
}

\author{
Sebastian Szmit • Michal Jank • Henryk Maciejewski • \\ Pawel Balsam • Magdalena Lój • Krzysztof J. Filipiak • \\ Tomasz Motyl • Grzegorz Opolski
}

Received: 9 March 2013 / Revised: 29 July 2013 / Accepted: 30 July 2013 / Published online: 22 August 2013

(C) The Author(s) 2013. This article is published with open access at Springerlink.com

\begin{abstract}
Anticancer treatment with the human epidermal growth factor receptor (HER) 2 inhibitors can lead to significant myocardial dysfunction. The primary aim of the study was to estimate the possible association between gene expression in the ErbB signaling pathway and selected clinical event data in patients with acute heart failure. Twenty-four patients (19 males), aged 68.6 \pm 12.3 years, were diagnosed and treated due to acute heart failure. The globaltest method was used for the correlation between blood nuclear cells' gene expression in the ErbB pathway (KEGG pathway id 04012) and important clinical data. Decreased expression of ErbB2/HER2 was found to be associated with the release of troponin and the need for inotropic support, whereas decreased neuregulin 1 (NRG1) expression was found to be associated with a decrease of ejection fraction below $40 \%$ (globaltest $p$-value $<0.05$ ). In summary, the ErbB signaling pathway and, especially, HER2/ErbB2 receptor expression are significantly associated with some of the recognized, clinically significant
\end{abstract}

S. Szmit $\cdot$ P. Balsam $\cdot$ K. J. Filipiak $\cdot$ G. Opolski

First Department of Cardiology, Medical University of Warsaw,

Warsaw, Poland

S. Szmit $(\bowtie)$

Department of Pulmonary Circulation and Thromboembolic Diseases, Centre of Medical Postgraduate Education, European Health Centre Otwock, ul. Borowa 14/18, 05-400 Otwock, Poland e-mail: s.szmit@gmail.com

\section{S. Szmit}

Department of Oncology, Centre of Medical Postgraduate Education, European Health Centre Otwock, Otwock, Poland

M. Jank · M. Łój · T. Motyl

Department of Physiological Sciences, Faculty of Veterinary

Medicine, Warsaw University of Life Sciences, Warsaw, Poland

H. Maciejewski

Institute of Computer Engineering, Control and Robotics (I-6),

Wroclaw University of Technology, Wroclaw, Poland parameters of patients with acute heart failure. Evaluation of the molecular function of the HER2 receptor may be essential for the prognosis and targeted therapy of heart diseases.

Keywords Acute heart failure - HER2 receptor . Gene expression profile

\section{Introduction}

The ErbB family is composed of four plasma membranebound receptor tyrosine kinases, which are involved in molecular signaling related to cell growth and survival in many tumor types (Motoyama et al. 2002). The human epidermal growth factor receptor 2, known as HER2 (sometimes as Neu or ErbB2), is a member of this receptor family.

Targeting the HER2 receptor is a milestone in the treatment of selected patients with early and advanced breast cancer (Baselga et al. 2006; Nielsen et al. 2013). Anticancer efficacy is complicated by a new type of heart failure (Cheng and Force 2010; Perez 2008). There is evidence that trastuzumab (Criscitiello and Curigliano 2013; Procter et al. 2010; Russell et al. 2010), lapatinib (Perez et al. 2008a), and pertuzumab (Lenihan et al. 2012) blocking the ErbB2/ HER2-dependent signaling pathway may lead to the deterioration of left ventricular cardiac function.

Cardio-oncology, a new scientific discipline, aims at trying to find methods to prevent iatrogenic myocardial dysfunction during anticancer treatment (Curigliano et al. 2012; Opolski et al. 2011). The prevention of cardiotoxicity related to antiHER2 treatment seems to be essential.

On the other hand, cardiologists should be interested in what is the role of the molecular signaling pathway dependent on ErbB2/HER2 in patients with heart diseases.

The primary aim of this study was to estimate the possible association between gene expression in the ErbB signaling 
pathway and selected clinical event data in patients with acute heart failure (AHF).

\section{Methods}

\section{Patient characteristics}

The study enrolled 24 patients (19 males) with a history of heart disease who were admitted to the Cardiology Department of Warsaw Medical University with the diagnosis of AHF. The mean age of the patients was $68.6 \pm 12.3$ years. The pre-existing heart diseases were: (1) myocardial infarction in 18 cases or (2) left ventricular hypertrophy with mild mitral insufficiency in 6 cases. Before hospitalization, patients had received appropriate cardiological treatment: 18 were treated with angiotensinconverting enzyme inhibitors, 17 with beta-blockers, 10 with diuretics, another 7 with aldosterone antagonists, 18 with antiplatelet therapy, and 20 with statins. The causes of AHF was decompensation of the circulatory system due to: myocardial ischemia (6), fluids overload in previous heart failure (5), valve dysfunction deterioration (3), pulmonary infection (3), sudden increase of blood pressure (3), myocarditis (2), and supraventricular arrhythmia with very fast ventricular rate (2). The exclusion criteria were: myocardial infarction with ST elevation as a cause of AHF, pre-hospital cardiac arrest, pulmonary embolism or stroke, cancer or severe lung disease, and chronic kidney disease in previous history.

All patients were diagnosed and treated according to the actual guidelines of the European Society of Cardiology. Chest X-ray was performed in all patients to assess the degree of congestion in the lungs. The following laboratory tests were performed in all of the participants: complete blood count, serum sodium, potassium, urea, creatinine, albumin, liver enzymes, prothrombin time, and troponin. Doppler echocardiography was performed to evaluate the segmental and global systolic function of the left and right ventricles, diastolic ventricular function, morphology, and function of the heart valves.

The study was approved by the local ethics committee of the Medical University of Warsaw and all participants gave written informed consent.

RNA isolation, validation, labeling, and hybridization

Blood samples were drawn just after admission to the intensive care unit, before beginning any treatment. They were obtained from the cephalic vein of the forearm, into PAXGene tubes (Qiagen, USA). Duplicate samples were obtained from each patient. Total RNA from peripheral blood nuclear cells was isolated using a PAXgene Blood RNA kit (Qiagen, USA). Isolated RNA samples were dissolved in RNase-free water, and the RNA quantity was measured with the use of NanoDrop (NanoDrop Technologies, USA). Samples with an adequate amount of RNA were treated with DNase I to eliminate DNA contamination and then purified using an RNeasy MiniElute Cleanup kit (Qiagen, Germany). Analysis of the final RNA quality and integrity was performed with a Bioanalyzer from Agilent Technologies (USA).

The gene expression profile analysis was performed using SurePrint G3 Hmn GE 8x60K (Agilent Technologies, USA). Each slide contained eight microarrays representing about 60,000 predicted human mRNAs. Experiments were performed using a common reference design, where a common reference was a pool of equal amounts of RNA from all the patients. On each two-color microarray, we hybridized $100 \mathrm{ng}$ of total RNA isolated from individual patients and $100 \mathrm{ng}$ of total RNA from the pool. Sample labeling, amplification, and microarray hybridization was performed with the use of appropriate kits supplied by the manufacturer of the microarrays (Agilent Technologies, USA), according to manufacturer's protocols (Agilent Technologies, USA). The acquisition and analysis of hybridization intensities were performed using an Agilent DNA microarray scanner.

Statistical analysis

\section{Data pre-processing}

The probe data were loess normalized, and probes replicated in the array were averaged. The log-ratio of the sample to reference signal was calculated and the data were mediancentered.

\section{Correlation of the expression of genes in the ErbB signaling} pathway with clinical event data

Association of the expression of genes in the ErbB pathway (Kyoto Encyclopaedia of Genes and Genomes: KEGG pathway id 04012) with clinical data was analyzed using the globaltest method (Goeman et al. 2004). The globaltest method is used to test the null hypothesis of no association of genes in the pathway with the selected clinical event. We tested association with the following clinical data observed in 24 patients:

1. Need for inotropic therapy: yes vs. no

2. Pulmonary edema: yes vs. no

3. Standard troponin I level: elevated vs. value in normal range

4. Ejection fraction of left ventricle (EF): supra- vs. inframedian

5. Duration of hospitalization (days): supra- vs. inframedian

6. 30 days follow-up: improvement vs. no improvement to NYHA class I/II 
The analyses were performed with the globaltest R/ Bioconductor package. The significant genes were selected based on the globaltest $p$-value $<0.05$.

\section{Results}

At the time of admission to the intensive care unit, before beginning any treatment, nine patients were recognized with pulmonary edema diagnosis and seven patients needed inotropic therapy. Moreover, 11 patients had elevated levels of troponin. The baseline hemodynamic parameters were recorded: (1) blood pressure: median $=140 / 70 \mathrm{mmHg}$ [range: 60/40-200/120]; (2) heart rate: median $=115 / \mathrm{min}$ [range 95160 ]; (3) NTproBNP: median $=6,550 \mathrm{pg} / \mathrm{ml}$ [range: 1,100 $17,700]$.

Biplane volume determination by two-dimensional echocardiography was used to evaluate the left ventricular ejection fraction and $\mathrm{EF}=40 \%$ was the median value [range: 15 $56 \%$. A period of 12 days resulted as the median value of hospitalization time, with a range between 5-58 days. It means that 12 patients needed hospitalization longer than 12 days. During 30 days of observation, 12 patients have experienced improvement to NYHA class I/II.

Analysis of the association of the expression of genes in the ErbB pathway with selected clinical data of patients revealed a significant association of some ErbB genes with the troponin level, ejection fraction, and need for inotropic therapy (Table 1). The significant genes were selected based on the globaltest $p$-value $<0.05$ (Table 2).

Analysis of the association of the ErbB pathway genes with the troponin level revealed that patients with an elevated level of troponin have decreased expression of two genes, namely, ERBB2 and AKT (phosphoinositide 3-kinase, PI3K, the signaling pathway activated by HER2) (see Fig. 1: expression signal below 0), whereas in patients with a low troponin level, ERBB2 and AKT are upregulated (see Fig. 1: signal is above 0).

Analysis of the association of the ErbB pathway genes with ejection fraction value revealed that patients with ejection fraction $>40 \%$ have higher expression signal of neuregulin 1 (NRG1) (see Fig. 2: expression signal above 0), whereas in patients with ejection fraction $<40 \%, \mathrm{NRG1}$ is downregulated (see Fig. 2: this signal is below 0). Of interest is that the microarray contained two different probes of NRG1, and both of them have the same expression pattern.

Analysis of the association of the ErbB pathway genes with inotropic therapy revealed nine genes which differed in expression in patents with and without the need for inotropic therapy. The largest differences were observed in the cases of transforming growth factor alpha (TGFA) and AKT1.

Analysis of the association of the ErbB pathway genes in "high-risk patients" was represented by two or three out of the following: low EF, need for inotropic therapy, elevated troponin
Table 1 Characteristics of the patients according to the assumptions of the study. The presented troponin level, ejection fraction, and need for inotropic therapy were found to be significantly associated with some ErbB genes expression

\begin{tabular}{|c|c|c|c|}
\hline Patient no. & $\begin{array}{l}\text { Elevated level } \\
\text { of troponin }\end{array}$ & $\begin{array}{l}\text { Ejection } \\
\text { fraction }<40 \%\end{array}$ & $\begin{array}{l}\text { Need for inotropic } \\
\text { therapy }\end{array}$ \\
\hline 1 & Yes & Yes & Yes \\
\hline 2 & Yes & Yes & Yes \\
\hline 3 & Yes & Yes & Yes \\
\hline 4 & Yes & Yes & No \\
\hline 5 & Yes & Yes & No \\
\hline 6 & Yes & Yes & No \\
\hline 7 & Yes & Yes & No \\
\hline 8 & Yes & Yes & No \\
\hline 9 & Yes & No & Yes \\
\hline 10 & Yes & No & No \\
\hline 11 & Yes & No & No \\
\hline 12 & No & Yes & Yes \\
\hline 13 & No & Yes & No \\
\hline 14 & No & Yes & No \\
\hline 15 & No & Yes & No \\
\hline 16 & No & No & Yes \\
\hline 17 & No & No & Yes \\
\hline 18 & No & No & No \\
\hline 19 & No & No & No \\
\hline 20 & No & No & No \\
\hline 21 & No & No & No \\
\hline 22 & No & No & No \\
\hline 23 & No & No & No \\
\hline 24 & No & No & No \\
\hline
\end{tabular}

level (10 patients, see Table 1), which appeared to significantly decrease the expression of two genes (see Fig. 4). One of these two genes is ERBB2, with expression signal below 0 .

\section{Discussion}

The ErbB family of receptor tyrosine kinases couples the binding of extracellular growth factor ligands to intracellular

Table 2 Genes from the ErbB pathway were significantly associated with troponin level, ejection fraction value, and the need for inotropic therapy in patients with acute heart failure

\begin{tabular}{ll}
\hline Clinical event data & $\begin{array}{l}\text { Entrez gene } \\
\text { identification number }\end{array}$ \\
\hline Troponins & 2064,208 \\
EF & 3084 \\
Inotropic therapy & $2064,5296,5609,207,5294,2475$, \\
& $6464,1950,7039$ \\
\hline
\end{tabular}




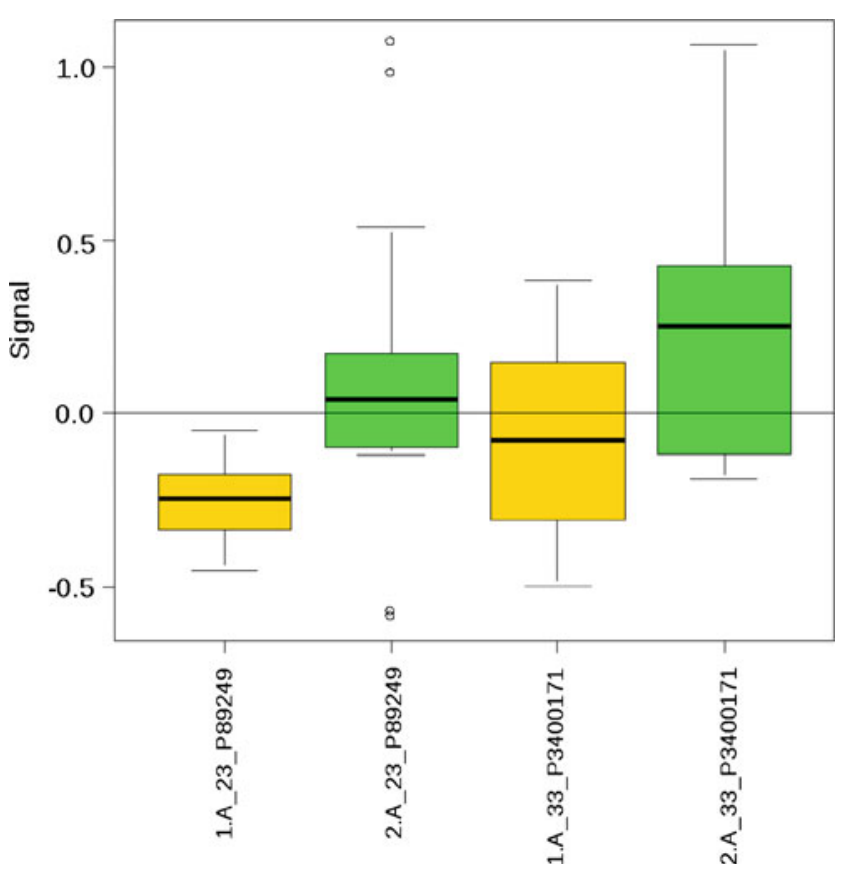

\begin{tabular}{|l|l|l|l|l|}
\hline ProbeName & GenelD & p-value & abbreviation & Full name \\
\hline A_23_P89249 & 2064 & 0.02235663 & $\begin{array}{l}\text { ERBB2 } \\
\text { (HER2) }\end{array}$ & $\begin{array}{l}\text { v-erb-b2 erythroblastic leukemia viral oncogene homolog } \\
\text { 2, neuro/glioblastoma derived oncogene homolog }\end{array}$ \\
\hline A_33_P3400171 & 208 & 0.03680284 & AKT2 & v-akt murine thymoma viral oncogene homolog 2 \\
\hline
\end{tabular}

Fig. 1 Expression of genes in the ErbB pathway were significantly associated with the troponin level. Group 1 (yellow) represents the expression of a gene in the group of patients who show elevated level of troponin; group 2 (green) represents patients with low troponin level. The genes shown in this figure realize globaltest $p$-values $<0.05$. The "whiskers" extend to the most extreme data point which is no more than 1.5 times the interquartile range (IQR) from the box. If a point lies further than 1.5 times the IRQ, then it is marked with a circle (and can be considered an outlier)

signaling pathways, regulating diverse biologic responses, including proliferation, differentiation, cell motility, and survival. One of the four members of this family is ErbB2(HER2) and the HER2/ErbB2-dependent signaling pathway is probably responsible for the proper myocardium structure, contractility, and function, despite the negative influence of ischemia, inflammation, hypertension, or toxins (Negro et al. 2004; Sawyer et al. 2002; Chien 2006). The HER2 receptor is responsible for the activation of transcription factor AP-1 (involved in heart muscle hypertrophy) and nuclear factor kappa B (involved in the response to oxidative stress) (Speyer 2002). Molecular studies indicate that ErbB2 plays a key role in dilated cardiomyopathy prevention (Crone et al. 2002). Mice with ErbB2 gene deletion exhibit gradually developing systolic heart dysfunction with heart ventricles distension and myocardium thinning (Ozcelik et al. 2002). However, the binding of neuregulin-1 (NRG-1) to the HER2 receptor is cardioprotective in mice (Liu et al. 2005).

The wide use of anti-HER2/ErbB2 therapies (trastuzumab, lapatinib, pertuzumab) in oncology resulted in a huge increase of iatrogenic cardiac dysfunction or heart failure in patients with breast cancer. The most dramatic data were reported by Seidman et al. (2002), who showed that trastuzumab administered simultaneously with cardiotoxic doxorubicin resulted in significant systolic myocardial dysfunction in every third woman. The trastuzumab-induced heart failure poses a few important features. Firstly, the clinical effect is not dosedependent and the disease level is variable, from subclinical decrease in the left ventricle ejection fraction to end-stage heart failure with signs of NYHA class IV. This has also been shown in HERA (Suter et al. 2007), NSABP B31 (Tan-Chiu et al. 2005), and N9831 studies (Perez et al. 2008b). Secondly, no ultrastructural changes in heart muscle has been observed (Ewer et al. 2002; Valero et al. 2004). Thirdly, in the majority of patients, the systolic heart dysfunction is reversible (Ewer et al. 2005). Sometimes, the normalization of systolic heart function occurs spontaneously after anti-HER-2 drugs withdrawal, but, in many cases, pharmacological treatment is required (Szmit et al. 2010).

The presence of cardiologic complications after anti-HER2 drugs use in oncologic patients requires the clarification of at least three aspects of this therapy, namely: if HER-2 receptor plays an important role in cardioprotection, so why do not all patients experience heart failure during anti-HER2 therapy? Why do we not see the dose-dependent action of the drug and the clinical picture could differ in intensity of clinical signs?

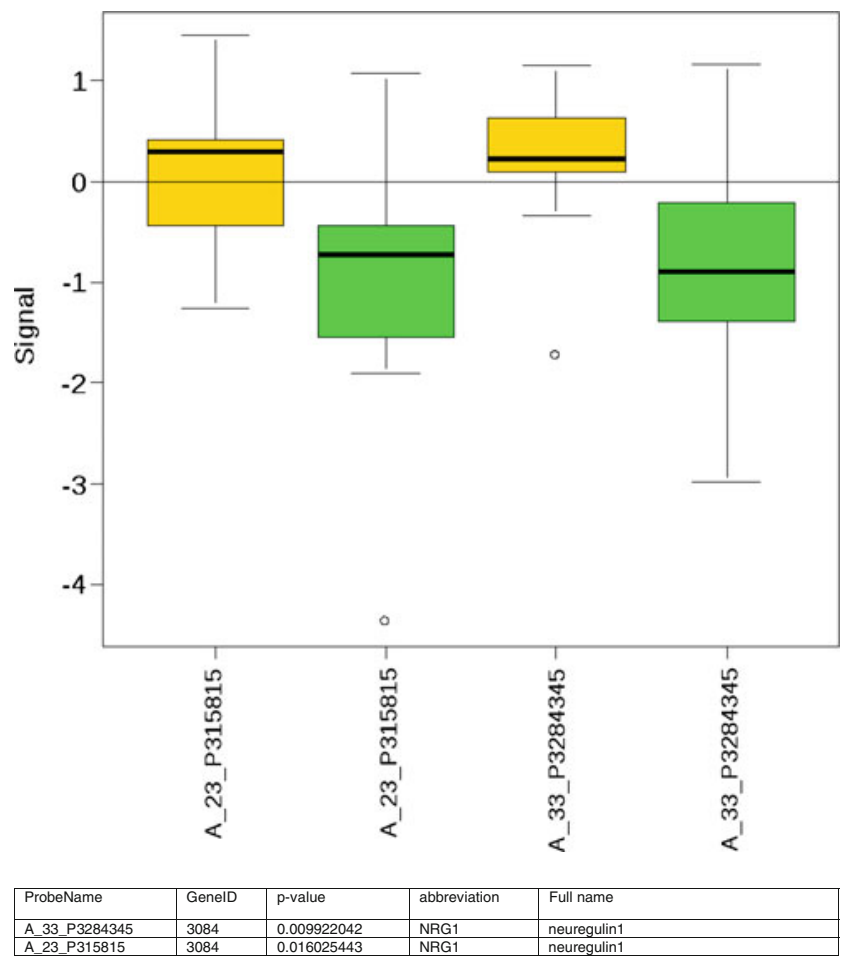

Fig. 2 Expression of genes in the ErbB pathway significantly associated with the ejection fraction value. Group 1 (yellow) represents the expression of a gene in the group of patients who show a level of EF of at least 40; group 2 (green) represents patients with EF level below 40 . The genes shown in this figure realize globaltest $p$-values $<0.05$ 


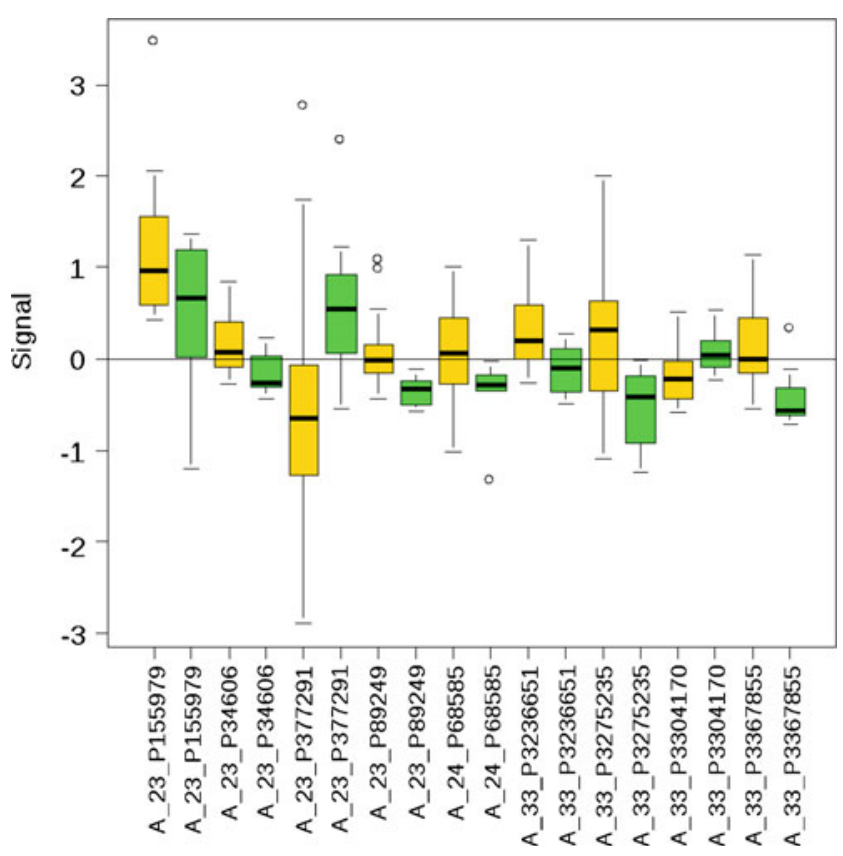

\begin{tabular}{|c|c|c|c|c|}
\hline ProbeName & GenelD & $p$-value & abbreviation & Full name \\
\hline A_23_P89249 & 2064 & 0.01275962 & $\begin{array}{l}\text { ERBB2 } \\
\text { (HER2) }\end{array}$ & $\begin{array}{l}\text { v-erb-b2 erythroblastic leukemia viral oncogene homolog } \\
\text { 2, neuro/glioblastoma derived oncogene homolog }\end{array}$ \\
\hline A_33_P3367855 & 5296 & 0.01604003 & PIK3R2 & phosphoinositide-3-kinase, regulatory subunit 2 (beta) \\
\hline $\begin{array}{ll}\text { A_33_P3236651 } \\
\text { A 33P327525 }\end{array}$ & 5609 & 0.01735023 & \begin{tabular}{|l|l|} 
MAP2K7 \\
AKT1 \\
\end{tabular} & mitogen-activated protein kinase kinase 7 \\
\hline $\begin{array}{l}\text { A_3_3_P325030 } \\
\text { A_33_P304170 }\end{array}$ & \begin{tabular}{|l|}
207 \\
5294 \\
\end{tabular} & $\begin{array}{l}0.02362099 \\
0.02390056 \\
\end{array}$ & \begin{tabular}{|l|} 
AKT1 \\
PIK3CG \\
\end{tabular} & $\begin{array}{l}\text { v-akt murine thymoma viral oncogene homolog } 1 \\
\text { phosphatidylinositol-4,5-bisphosphate 3-kinase, catalytic } \\
\text { subunit gamma }\end{array}$ \\
\hline A_23_P34606 & 2475 & 0.04074415 & MTOR & $\begin{array}{l}\text { mechanistic target of rapamycin (serine/threonine } \\
\text { kinase) }\end{array}$ \\
\hline A_24_F & 6464 & 0.04 & SHC1 & $\begin{array}{l}\text { SHC (Src homology } 2 \text { domain containing) transforming } \\
\text { protein } 1\end{array}$ \\
\hline & 19 & & $E C$ & epidermal growth factor \\
\hline A_23_P377291 & 7039 & 0.04813916 & TGFA & transforming growth factor alpha \\
\hline
\end{tabular}

Fig. 3 The expression of genes in the ErbB pathway was significantly associated with inotropic therapy. Group 1 (yellow) represents the expression of a gene in the group of patients with no inotropic therapy; group 2 (green) represents patients with inotropic therapy. The genes shown in this figure realize globaltest $p$-values $<0.05$

And, finally, why after the anti-HER2 drug discontinuation, do not all the patients experience the full normalization of ejection fraction of the left ventricle?

The answer may be found in the study of Cardinale et al. (2010), who showed that trastuzumab administration could induce myocardial damage, resulting in increased plasma troponin level. These results show also that, probably, we do not know all the aspects of HER-2 inhibition in oncology. That is why we decided to approach this issue differently and check whether the clinical picture of patients with AHF is associated with ErbB2/HER-2 pathway activity. In the present study, we were able to correlate some clinical features with the differential expression of some genes involved in the ErbB pathway in patients with AHF. The measurement of the gene expression were performed using DNA microarrays, so it is only semi-quantitative analysis; however, it allowed not only for the correlation of individual clinical parameters with the specific gene(s), but also for the verification as to whether the changes in clinical parameters are associated with increased or decreased expression of specific gene(s).
Although our patients were not receiving either trastuzumab or lapatinib, we were able to observe the similar clinical situation as seen during anti-HER2 treatment. In patients with AHF and increased troponin level, the ErbB2(HER2) expression is also decreased (Fig. 1). We do not know, however, the sequence of these phenomena, whether troponins release was the cause or the consequence of decreased ErbB2 expression. Since trastuzumab administration inhibits the ErbB2 expression and this inhibition results in troponins release possibly in some patients before AHF, there was an unspecific decrease in ErbB2 expression and when they experienced AHF, they released a high level of troponin. In our patients with low troponin level, in the range of normal values, the ErbB2/HER2 expression was unchanged (or slightly increased). So the main question remains open: why do patients with high troponin level have decreased ErbB2/HER2 expression? It is also worth noting that the decreased ErbB2/HER-2 expression was significantly associated with the need for inotropic therapy (Fig. 3). Moreover, the decreased ErbB2/HER-2 expression characterized the "high-risk patients" with two or three of the following observed clinical events simultaneously: low EF, need for inotropic therapy, elevated troponin level (Fig. 4).

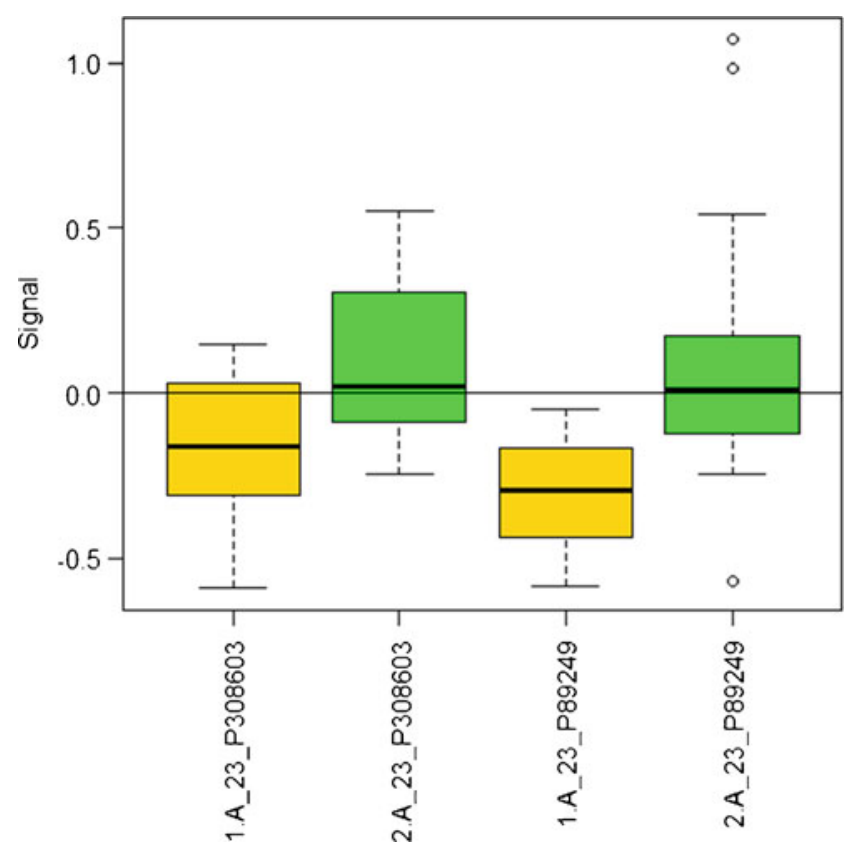

\begin{tabular}{|l|l|l|l|l|}
\hline ProbeName & GenelD & p-value & abbreviation & Full name \\
\hline A_23_P89249 & 2064 & 0.01038063 & ERBB2 (HER2) & $\begin{array}{l}\text { V-rbb-b2 erythroblastic leekemia viral } \\
\text { oncogene homolog 2, neuro/glioblastoma } \\
\text { derived oncogene homolog }\end{array}$ \\
\hline A_23_P308603 & 6714 & 0.01687726 & SRC & $\begin{array}{l}\text { v-sce sarcoma (Schmidt-Ruppin A-2) viral } \\
\text { oncogene homolog (avian) }\end{array}$ \\
\hline
\end{tabular}

Fig. 4 The expression of genes in the ErbB pathway in "high-risk patients" (yellow) is represented by two or three out of the following: low EF, need for inotropic therapy, elevated troponin level $(n=10 \mathrm{pa}-$ tients, see Table 1). For comparison, "low-risk patients" (green) were characterized by none or only one of the mentioned clinical events. The genes shown in this figure realize globaltest $p$-values $<0.05$ 
As mentioned earlier, the binding of neuregulin-1 (NRG-1) to the HER-2 receptor has cardioprotective action. There are suggestions that NRG1 may become a new drug for the treatment of heart failure (Jabbour et al. 2011; Yan and Morgan 2011). Ky et al. (2009) presented that circulating NRG-1beta was significantly elevated in patients with worse chronic heart failure severity. Moreover, circulating NRG-1beta together with natriuretic peptide may provide better risk stratification than each biomarker individually.

The cardioprotective action of NRG-1 is also clearly seen in our study, since we identified an association between low NRG-1 expression and decreased ejection fraction below $40 \%$ (Fig. 2). In oncological patients, the decrease of ejection fraction below 40 is a factor requiring anti-HER-2 therapy withdrawal. Based on our study, we could conclude that EF $<40 \%$ is associated with decreased expression of NRG1 and the lack of the cardioprotective action of this molecule. The patient characteristics (Table 1) show that, between 11 patients with increased troponin level and molecularly decreased ErbB, simultaneously, eight patients also have decreased ejection fraction below $40 \%$ and molecularly decreased NRG1. The simultaneous presence of $\mathrm{EF}<40 \%$ and increased troponin level suggest severe myocardial damage and increased risk of death/ worse prognosis. Our studies suggest that this clinical picture is associated with decreased expression of ErbB and neuregulin-1 (NGR-1) on the molecular level. It means that, in some of our patients, the occurrence of AHF changed the expression of the ErbB pathway comparably to the anti-HER2 treatment. So, we hypothesize that the changes in ErbB pathway expression (decreased ErbB and NRG1 expression) could be the marker of heart dysfunction not only in oncological patients but also in otherwise healthy population. The molecular function of HER2 receptor should become an essential factor in the prognosis and planning of targeted prevention of myocardial damage.

The presented study has some important limitations. First of all, the obtained results were gathered from a very low number of patients and there is no real control group. It is true that the recruitment of patients with AHF into clinical trials is very difficult. The rhetorical question is how to define a control group: AHF without history of heart disease or compensated chronic heart failure? Second, patients from daily practice were observed and analyzed, so there were no strong exclusion criteria. It means that a heterogeneous group of patients was recruited. There were different reasons for the occurrence of AHF, which may be associated with possible differences in gene expression (ischemic vs. infectious vs. hemodynamic reasons). On the other hand, it is interesting that the expression of ErbB2/HER2 and its mediator (NRG1) achieved such a statistically significant level. The presented results need multicenter future research with the evaluation of clinical importance in long-term follow-up.

\section{Conclusions}

Our study showed that the ErbB signaling pathway and, especially, ErbB2/HER2 receptor expression are significantly associated with some clinical parameters of patients with acute heart failure. Decreased expression of ErbB2/HER2 is associated with the release of troponins and the need for inotropic therapy, whereas decreased NRG1 expression is associated with a decrease of ejection fraction below $40 \%$. Therefore, we could conclude that the measurement of the expression of genes belonging to the ErbB signaling pathway could become the prognostic factor not only in patients undergoing anticancer anti-HER2 therapy, but in all patients with heart diseases.

Acknowledgments This research was funded by a grant from the Polish Cardiac Society.

Conflict of interest The authors do not have any conflict of interests to declare.

Open Access This article is distributed under the terms of the Creative Commons Attribution License which permits any use, distribution, and reproduction in any medium, provided the original author(s) and the source are credited.

\section{References}

Baselga J, Perez EA, Pienkowski T, Bell R (2006) Adjuvant trastuzumab: a milestone in the treatment of HER-2-positive early breast cancer. Oncologist 11(Suppl 1):4-12

Cardinale D, Colombo A, Torrisi R, Sandri MT, Civelli M, Salvatici M, Lamantia G, Colombo N, Cortinovis S, Dessanai MA, Nolè F, Veglia F, Cipolla CM (2010) Trastuzumab-induced cardiotoxicity: clinical and prognostic implications of troponin I evaluation. J Clin Oncol 28(25):3910-3916

Cheng H, Force T (2010) Molecular mechanisms of cardiovascular toxicity of targeted cancer therapeutics. Circ Res 106:21-34

Chien KR (2006) Herceptin and the heart-a molecular modifier of cardiac failure. N Engl J Med 354(8):789-790

Criscitiello C, Curigliano G (2013) HER2 signaling pathway and trastuzumab cardiotoxicity. Future Oncol 9(2):179-181

Crone SA, Zhao YY, Fan L, Gu Y, Minamisawa S, Liu Y, Peterson KL, Chen J, Kahn R, Condorelli G, Ross J Jr, Chien KR, Lee KF (2002) ErbB2 is essential in the prevention of dilated cardiomyopathy. Nat Med 8:459-465

Curigliano G, Cardinale D, Suter T, Plataniotis G, de Azambuja E, Sandri MT, Criscitiello C, Goldhirsch A, Cipolla C, Roila F; ESMO Guidelines Working Group (2012) Cardiovascular toxicity induced by chemotherapy, targeted agents and radiotherapy: ESMO Clinical Practice Guidelines. Ann Oncol 23(Suppl 7):vii155-vii166

Ewer MS, Vooletich MT, Valero V, Higano CS, Benjamin RS (2002) Trastuzumab (Herceptin) cardiotoxicity: clinical course and cardiac biopsy correlations. Proc Am Soc Clin Oncol 21:123a (abstr. 489)

Ewer MS, Vooletich MT, Durand JB, Woods ML, Davis JR, Valero V, Lenihan DJ (2005) Reversibility of trastuzumab-related cardiotoxicity: new insights based on clinical course and response to medical treatment. J Clin Oncol 23(31):7820-7826 
Goeman JJ, van de Geer SA, de Kort F, van Houwelingen HC (2004) A global test for groups of genes: testing association with a clinical outcome. Bioinformatics 20(1):93-99

Jabbour A, Hayward CS, Keogh AM, Kotlyar E, McCrohon JA, England JF, Amor R, Liu X, Li XY, Zhou MD, Graham RM, Macdonald PS (2011) Parenteral administration of recombinant human neuregulin-1 to patients with stable chronic heart failure produces favourable acute and chronic haemodynamic responses. Eur J Heart Fail 13(1):83-92

Ky B, Kimmel SE, Safa RN, Putt ME, Sweitzer NK, Fang JC, Sawyer DB, Cappola TP (2009) Neuregulin-1 beta is associated with disease severity and adverse outcomes in chronic heart failure. Circulation 120(4):310-317

Lenihan D, Suter T, Brammer M, Neate C, Ross G, Baselga J (2012) Pooled analysis of cardiac safety in patients with cancer treated with pertuzumab. Ann Oncol 23(3):791-800

Liu FF, Stone JR, Schuldt AJ, Okoshi K, Okoshi MP, Nakayama M, Ho KK, Manning WJ, Marchionni MA, Lorell BH, Morgan JP, Yan X (2005) Heterozygous knockout of neuregulin-1 gene in mice exacerbates doxorubicin-induced heart failure. Am J Physiol Heart Circ Physiol 289:H660-H666

Motoyama AB, Hynes NE, Lane HA (2002) The efficacy of ErbB receptor-targeted anticancer therapeutics is influenced by the availability of epidermal growth factor-related peptides. Cancer Res 62(11):3151-3158

Negro A, Brar BK, Lee KF (2004) Essential roles of Her2/erbB2 in cardiac development and function. Recent Prog Horm Res 59:1-12

Nielsen DL, Kümler I, Palshof JA, Andersson M (2013) Efficacy of HER2-targeted therapy in metastatic breast cancer. Monoclonal antibodies and tyrosine kinase inhibitors. Breast 22(1):1-12

Opolski G, Krzakowski M, Szmit S, Banach J, Chudzik M, Cygankiewicz I, Drożdż J, Filipiak KJ, Grabowski M, Kaczmarek K, Kochman J, Lewek J, Maciejewski M, Miśkiewicz Z, Niwińska A, Pieńkowski T, Piestrzeniewicz K, Sinkiewicz W, Wranicz JK, Zawilska K; Task Force of National Consultants in Cardiology and Clinical Oncology (2011) Recommendations of National Team of Cardiologic and Oncologic Supervision on cardiologic safety of patients with breast cancer. The prevention and treatment of cardiovascular complications in breast cancer. The Task Force of National Consultants in Cardiology and Clinical Oncology for the elaboration of recommendations of cardiologic proceeding with patients with breast cancer. Kardiol Pol 69(5):520-530

Ozcelik C, Erdmann B, Pilz B, Wettschureck N, Britsch S, Hübner N, Chien KR, Birchmeier C, Garratt AN (2002) Conditional mutation of the ErbB2 (HER2) receptor in cardiomyocytes leads to dilated cardiomyopathy. Proc Natl Acad Sci U S A 99:8880-8885

Perez EA (2008) Cardiac toxicity of ErbB2-targeted therapies: what do we know? Clin Breast Cancer 8(Suppl 3):S114-S120

Perez EA, Koehler M, Byrne J, Preston AJ, Rappold E, Ewer MS (2008a) Cardiac safety of lapatinib: pooled analysis of 3689 patients enrolled in clinical trials. Mayo Clin Proc 83(6):679-686

Perez EA, Suman VJ, Davidson NE, Sledge GW, Kaufman PA, Hudis CA, Martino S, Gralow JR, Dakhil SR, Ingle JN, Winer EP, Gelmon KA, Gersh BJ, Jaffe AS, Rodeheffer RJ (2008b) Cardiac safety analysis of doxorubicin and cyclophosphamide followed by paclitaxel with or without trastuzumab in the North Central Cancer Treatment Group N9831 adjuvant breast cancer trial. J Clin Oncol 26(8):1231-1238

Procter M, Suter TM, de Azambuja E, Dafni U, van Dooren V, Muehlbauer S, Climent MA, Rechberger E, Liu WT, Toi M, Coombes RC, Dodwell D, Pagani O, Madrid J, Hall M, Chen SC, Focan C, Muschol M, van Veldhuisen DJ, Piccart-Gebhart MJ (2010) Longer-term assessment of trastuzumab-related cardiac adverse events in the Herceptin Adjuvant (HERA) trial. J Clin Oncol 28(21):3422-3428

Russell SD, Blackwell KL, Lawrence J, Pippen JE Jr, Roe MT, Wood F, Paton V, Holmgren E, Mahaffey KW (2010) Independent adjudication of symptomatic heart failure with the use of doxorubicin and cyclophosphamide followed by trastuzumab adjuvant therapy: a combined review of cardiac data from the National Surgical Adjuvant Breast and Bowel Project B-31 and the North Central Cancer Treatment Group N9831 clinical trials. J Clin Oncol 28(21):3416-3421

Sawyer DB, Zuppinger C, Miller TA, Eppenberger HM, Suter TM (2002) Modulation of anthracycline-induced myofibrillar disarray in rat ventricular myocytes by neuregulin-1 beta and anti-erbB2: potential mechanism for trastuzumab-induced cardiotoxicity. Circulation 105(13):1551-1554

Seidman A, Hudis C, Pierri MK, Shak S, Paton V, Ashby M, Murphy M, Stewart SJ, Keefe D (2002) Cardiac dysfunction in the trastuzumab clinical trials experience. J Clin Oncol 20(5):1215-1221

Speyer J (2002) Cardiac dysfunction in the trastuzumab clinical experience. J Clin Oncol 20:1156-1157

Suter TM, Procter M, van Veldhuisen DJ, Muscholl M, Bergh J, Carlomagno C, Perren T, Passalacqua R, Bighin C, Klijn JG, Ageev FT, Hitre E, Groetz J, Iwata H, Knap M, Gnant M, Muehlbauer S, Spence A, Gelber RD, Piccart-Gebhart MJ (2007) Trastuzumab-associated cardiac adverse effects in the herceptin adjuvant trial. J Clin Oncol 25(25):3859-3865

Szmit S, Kurzyna M, Glówczynska R, Grabowski M, Kober J, Czerniawska J, Filipiak KJ, Opolski G, Szczylik C (2010) Manageability of acute severe heart failure complicated with left ventricular thrombosis during therapy for breast cancer. Int Heart J 51(2):141-145

Tan-Chiu E, Yothers G, Romond E, Geyer CE Jr, Ewer M, Keefe D, Shannon RP, Swain SM, Brown A, Fehrenbacher L, Vogel VG, Seay TE, Rastogi P, Mamounas EP, Wolmark N, Bryant J (2005) Assessment of cardiac dysfunction in a randomized trial comparing doxorubicin and cyclophosphamide followed by paclitaxel, with or without trastuzumab as adjuvant therapy in node-positive, human epidermal growth factor receptor 2-overexpressing breast cancer: NSABP B-31. J Clin Oncol 23(31):7811-7819

Valero V, Gill E, Paton V, Chang H-Y, Buzdar AU, Park G, Hortobagyi G, Ewer M (2004) Normal cardiac biopsy results following coadministration of doxorubicin (A), cyclophosphamide (C) and trastuzumab $(\mathrm{H})$ to women with HER2 positive metastatic breast cancer. Proc Am Soc Clin Oncol. 23:20 (abstr. 572)

Yan X, Morgan JP (2011) Neuregulin1 as novel therapy for heart failure. Curr Pharm Des 17(18):1808-1817 